\title{
EVALUASI PENGUKURAN WAKTU KERJA DENGAN METODE TIME MOTION STUDY PADA DIVISI FINAL INSPECTION PT GAJAH TUNGGAL TBK
}

\author{
DIAH SEPTIYANA ${ }^{1)}$, \& MAHFUDZ $^{2)}$ \\ Program Studi Teknik Industri, Fakultas Teknik, Universitas Muhammadiyah Tangerang \\ Jalan Perintis Kemerdekaan I No.33, Cikokol, Babakan, \\ Kota Tangerang, Banten, 15118, Indonesia \\ Email:dee.septie@gmail.com ${ }^{1)}$,mahfudzmashter@gmail.com ${ }^{2)}$
}

\begin{abstract}
ABSTRAK
PT. Gajah Tunggal Tbk merupakan perusahaan yang memproduksi tube/ban dalam. Teknologi yang digunakan perusahaan tersebut masih sederhana sehingga kemampuan tenaga kerja berpengaruh besar terhadap kinerja perusahaan. Analisa gerak dan waktu, diperlukan untuk dapat meminimalkan gerakan kerja yang tidak efektif sehingga akan diperoleh waktu kerja yang optimal. Tujuan penelitian ini adalah (1) Untuk mengetahui waktu standar sebelum perbaikan metode kerja dengan metode Time Motion Study, (2) Untuk mengetahui waktu standar setelah perbaikan metode kerja dengan metode Time Motion Study, (3)Untuk menganalisis faktor yang menyebabkan waktu kerja pada bagian OEM Final Inspection tidak optimal. Dalam penelitian ini dilakukan pengukuran waktu kerja secara langsung dengan metode Time Motion Study. Dan dianalisa kembali dengan menggunakan diagram fishbone. Faktor yang mempengaruhi kinerja tidak efektif yaitu Kurang disiplinnya operator karena budaya kerja, Belum adanya standar kerja (gerak dan waktu). Adanya proses menunggu Berdasarkan hasil perhitungan diperoleh hasil waktu standar sebelum perbaikan pada operator 1 yaitu 417 detik, operator 2 yaitu 474 detik, pada operator 3 yaitu 447 detik dan pada operator 4 yaitu 136 detik dan hasil waktu standar setelah perbaikan pada operator 1,2,3 dan 4 yaitu 332 detik, 457 detik, 374 detik dan 62 detik.
\end{abstract}

Kata Kunci: Waktu Standar, Time Motion Study, Pengukuran Kerja, Fishbone.

\section{PENDAHULUAN}

Setiap perusahaan akan berupaya keras untuk memenangkan persaingan yang ada di antara perusahaan-perusahaan yang menghasilkan produk sejenis. Untuk mewujudkan hal tersebut, maka dibutuhkan sumber daya yang memadai, seperti tenaga kerja, modal, bahan baku, mesin, peralatan, cara kerja, dan informasi pasar. Namun demikian, dari semua faktor-faktor produksi tersebut yang menjadi faktor utamanya, adalah tenaga kerja, karena tenaga kerja yang bersangkutanlah yang akan menjalankan roda perusahaan. Para tenaga kerja tersebut mempunyai keterampilan yang berbeda-beda, dari yang sangat terampil sampai yang biasa-biasa saja bahkan ada yang sangat lamban atau keterampilannya di bawah rata-rata pekerja lainnya. Dalam menghadapi persaingan yang ketat, ini, perusahaan berusaha agar dapat memenuhi permintaan konsumen sesuai dengan spesifikasi, jumlah, dan waktu yang diminta, serta dengan biaya minimum, dimana pada akhirnya semua hal tersebut mengarah pada keberhasilan perusahaan dalam mengolah sumberdayanya.

Melihat pentingnya pengukuran setiap aktivitas yang dilakukan perusahaan, maka dibutuhkan metode pengukuran yang akurat agar dapat memberikan informasi yang tepat atas waktu yang dibutuhkan dan efisiensi pergerakan setiap aktifitas untuk menghasilkan produk. Salah satu metode yang digunakan dalam melakukan pengukuran waktu atas aktifitas yang digunakan adalah dengan menggunakan metode time and motion study, dari metode tersebut dapat dilihat adanya pening- 
katan efektifitas waktu dan pergerakan sumber-sumber yang digunakan dibandingkan dengan hasil yang dicapai oleh perusahaan. Menurut Wignjosoebroto (2003), definisi time and motion study adalah sebuah pembelajaran sistematis dari sistem kerja dengan tujuan mengembangkan sistem dan metode yang lebih baik, menstandarkan system, untuk menentukan standar waktu dan melatih operator PT Gajah Tunggal tbk merupakan salah satu perusahaan yang bergerak dalam bidang otomotif yaitu pembuatan Tyre /Ban/tube.

Proses produksi PT Gajah Tunggal tbk dibagi menjadi empat kategori yaitu proses pengolahan bahan baku, proses penyambungan proses curing dan QC Final Inspection. Proses kerja di final inspection masih menggunakan mesin dengan bantuan tenaga manusia dimana pada bagian mesin dijalankan dengan operator manusia, hal yang sudah pasti terlihat adalah gerakan-gerakan yang membentuk kerja tersebut.

Dalam penelitian ini dilakukan pengukuran waktu kerja secara langsung dengan metode Time Motion Study dan dianalisa kembali dengan menggunakan diagram fishbone untuk mengetahui faktor faktor yang menyebabkan waktu kerja tidak optimal. Tujuan penelitian ini adalah untuk mengetahui hasil perbandingan waktu kerja sebelum penelitian dan sesudah penelitian, dan untuk mendapatkan waktu standar kerja, sehingga mendapatkan data alternatif menentukan metode kerja yang lebih baik dalam menyelesaikan suatu pekerjaan, sekaligus mengetahui waktu dan tiap-tiap gerakan kerja tersebut, sehingga dapat diketahui gerakan-gerakan yang sebenarnya tidak perlu dilakukan oleh operator atau yang biasa disebut gerakangerakan yang tidak optimal.

Dalam penelitian ini, permasalahan mengenai waktu kerja akan dititikberatkan pada:

1. Faktor apa saja yang menyebabkan waktu kerja tidak optimal pada bagian OEM Final Inspection?

2. Berapa waktu standar pada bagian OEM

Final Inspection yang didapat sebelum perbaikan dan sesudah perbaikan?

\section{LANDASAN TEORI}

1. Peta Kerja

Peta kerja merupakan alat komunikasi yang sistematis dan logis untuk menganalisa proses kerja mulai awal sampai akhir. Melalui peta kerja akan diperoleh informasi yang diperlukan untuk memperbaiki metode kerja, informasi tersebut antara lain adalah benda kerja berupa gambar kerja, jumlah, spesifikasi material, dimensi ukuran pekerjaan, dan lainlain. Informasi yang lain yaitu macam proses yang dilakukan, jenis dan spesifikasi mesin, peralatan produksi, dan lain-lain. Juga diperoleh informasi tentang waktu operasi untuk setiap proses atau elemen kegiatan dan total waktu penyelesaiannya serta kapasitas mesin (Wignjosoebroto, 2000)

\section{Peta Tangan Kiri dan Tangan Kanan}

Peta tangan kiri dan tangan kanan merupakan suatu alat dari studi gerakan untuk menemukan gerakan-gerakan yang efisien, yaitu gerakan-gerakan yang diperlukan untuk melaksanakan suatu pekerjaan. Peta ini menggambarkan semua gerakan-gerakan saat bekerja dan waktu menganggur yang dilakukan oleh tangan kiri dan tangan kanan, juga menunjukkan perbandingan antara tugas yang dibebankan pada tangan kiri dan tangan kanan ketika melakukan suatu pekerjaan. Dalam membuat peta operator akan lebih efektif kalau hanya 8 elemen gerakan Therbligh berikut ini yang digunakan, yaitu Reach (RE), Use (U), Grasp (G), Release (RL), Move (M), Delay (D), Position (P), Hold (H).

\section{Time \& Motion Study}

Motion study and time study adalah suatu studi tentang gerakan-gerakan yang dilakukan oleh pekerja untuk menyelesaikan pekerjaannya. Dengan studi ini ingin diperoleh gerakan-gerakan standar untuk penyelesaian suatu pekerjaan, yaitu rangkaian gerakangerakan yang efektif dan efisien. Studi mengenai ini dikenal sebagai studi ekonomi gerakan yaitu studi yang menitik beratkan pada penerapan prinsip-prinsip ekonomi gerakan. (Wignjosoebroto, 2003)

\section{METODE PENELITIAN}

Langkah-langkah pada penelitian ini adalah sebagai berikut: 


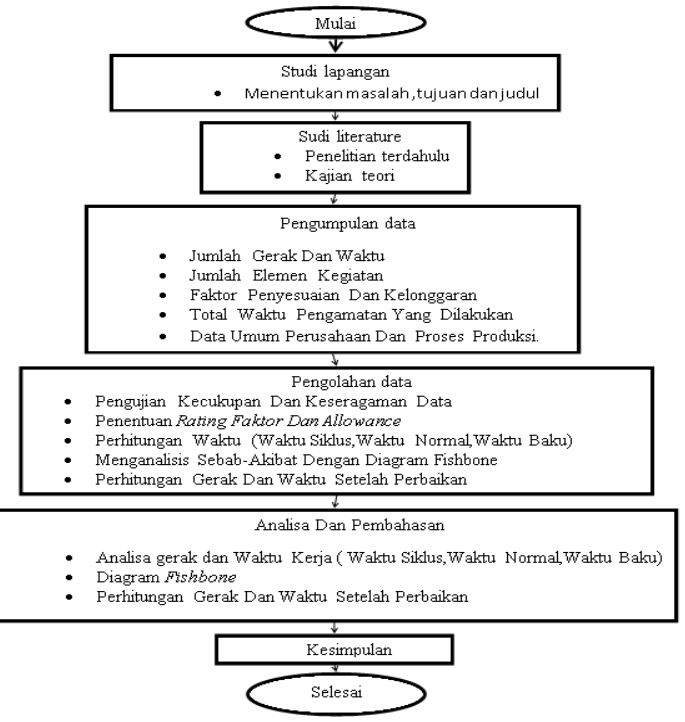

Gambar 1 Flowchart langkah langkah penelitian

\section{HASIL DAN PEMBAHASAN}

\section{Pengumpulan Data}

1) Perhitungan Gerak dan Waktu

Data waktu pengamatan sebanyak 12 kali dapat dilihat pada tabel berikut:

Tabel 1 Pengamatan waktu kerja Final Inspection

\begin{tabular}{|c|c|c|c|}
\hline \multicolumn{2}{|l|}{ Pasang Part dan Inflate tube } & \multicolumn{2}{|l|}{ Inspection } \\
\hline Langkan Kerja & $\begin{array}{c}\text { Rata-Rata } \\
\text { (detick })\end{array}$ & Langkah Kerja & $\begin{array}{l}\text { Rata-Rata } \\
\text { (detik) }\end{array}$ \\
\hline Merapikan Tube & 8.7 & Menjangkau Tube & \\
\hline $\mid \begin{array}{l}\text { Menarik Valve } \\
\text { Mengambi Part }\end{array}$ & & Meletakkan Tibe Di Meja Check & 35.5 \\
\hline $\begin{array}{l}\text { Mengambil Part } \\
\text { Memilah Part }\end{array}$ & 11.8 & Mengambil Kuas & 11.8 \\
\hline $\begin{array}{l}\text { Memilah Part } \\
\text { Mengarahkan Part }\end{array}$ & $\begin{array}{l}6.6 \\
7.2\end{array}$ & $\begin{array}{l}\text { Mengoles Luas Ke Airsabun } \\
\text { Memoles Tube }\end{array}$ & $\begin{array}{l}22.6 \\
587\end{array}$ \\
\hline Memasang Part & 39.3 & Memutar Tube & $\begin{array}{l}30.8 \\
11.8\end{array}$ \\
\hline Memutar Nut & 14.4 & Inspeksi & 92.5 \\
\hline Mengambil Selang Inflate & & Melepas Cup & \\
\hline Menekan Tombol Inflate & & Meletakkan Tube & \\
\hline Mengambil Cup & 11.6 & & \\
\hline Menggul irkan tube & & & \\
\hline Total & 294.2 & & \\
\hline Vakum \& L Labelling & & \multicolumn{2}{|l|}{ Booking Tube } \\
\hline Langkah Kerja & $\begin{array}{l}\text { Ratat-Rata } \\
\text { (detik) }\end{array}$ & Langkah Kerja & $\begin{array}{l}\text { Rata-Rata } \\
\text { (detik) }\end{array}$ \\
\hline Menjangkau Tube & 7.2 & Mengambil Tube dari storage sementara & 43.8 \\
\hline Memindahkan Ke Lori & 27.3 & Menjangkau Tube & 17.2 \\
\hline $\begin{array}{l}\text { Mendorong Lori ke Meja Vakum } \\
\text { Meninankaza Tube }\end{array}$ & 36.9 & Meletakkan Tube ke pallet & 6.2. \\
\hline $\begin{array}{l}\text { Werjangkaud Ibe } \\
\text { Meletakkantube ke Meja Vakum }\end{array}$ & & Menekan Tube & 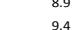 \\
\hline Memasukan Valve ke Lubang Vakum & & Pewarnaan/Cat Valve & 11.3 \\
\hline Menekan Valve & & & 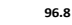 \\
\hline Memasukan inside core ke velave & 8.3 & & \\
\hline $\begin{array}{l}\text { menekann tombol Airjet } \\
\text { Memasukan ke lubang vakum }\end{array}$ & $\begin{array}{rl}5.8 & 0 \\
5 & 0\end{array}$ & & \\
\hline Mengambil cup & 11.4 & & \\
\hline $\begin{array}{l}\text { Memutar cup } \\
\text { Labelling }\end{array}$ & $\begin{array}{c}13.4 \\
8.5\end{array}$ & & \\
\hline $\begin{array}{l}\text { Labelling } \\
\text { Memindahkan Tube ke Lori }\end{array}$ & 40 & & \\
\hline Mengantarkan ke booking tube & 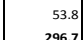 & & \\
\hline
\end{tabular}

2) Peta Tangan Kiri dan Tangan Kanan (PTKTK)

Pengukuran waktu dilakukan dengan mengamati peta tangan kiri dan tangan kanan setiap gerakan tangan.berikut ini peta tangan kiri dan tangan kanan (PTKTK) setiap elemen yang menggunakan gerakan tangan.
Tabel 2 PTKTK Part Tube Dan Inflate

\begin{tabular}{|c|c|c|c|}
\hline \multirow{2}{*}{ Tangan Kiri } & Waktu & \multirow{2}{*}{ Tangan Kanan } & Waktu \\
\hline & (detik) & & (detik) \\
\hline Memegang Ban & 2.2 & Memegang Tube & 2.2 \\
\hline Menarik Tube & 1.6 & Menarik Tube & 1.6 \\
\hline Sub Total & 3.8 & Sub Total & 3.8 \\
\hline \multirow{5}{*}{ Menunggu } & \multirow{5}{*}{19.9} & Mengambil Part & 3 \\
\hline & & Memilah Part & 1.7 \\
\hline & & Mengarahkan Part & 1.8 \\
\hline & & Memasang Part & 9.8 \\
\hline & & Memutar Nut & 3.6 \\
\hline Sub Total & 19.9 & Sub Total & 19.9 \\
\hline Sub Total x 5 Tube & 99.5 & Sub Total x 5 Tube & 99.5 \\
\hline Menunggu & 2.3 & Mengambil Selang Inflate & 2.3 \\
\hline Memegang Valve & 35.6 & Menekan Tombol Inflate & 35.6 \\
\hline Mengambil Cup & 2.9 & Standby Di Tombol & 2.9 \\
\hline Memutar Cup & 3.7 & Melepas Tombol & 3.7 \\
\hline Menunggu & 5.6 & Menggulirkan Tube & 5.6 \\
\hline Sub Total & 50.1 & Sub Total & 50.1 \\
\hline Sub Total x 5 Tube & 250.5 & Sub Total x 5 Tube & 250.5 \\
\hline Total Waktu Tiap Siklus & 353.8 & & 353.8 \\
\hline Jumlah Pcs Tiap Siklus & $5 \mathrm{Pcs}$ & & $5 \mathrm{Pcs}$ \\
\hline
\end{tabular}

Sumber: Data Pengamatan

Tabel 3 PTKTK Inspection

\begin{tabular}{|l|c|l|r|}
\hline \multirow{2}{*}{ Tangan Kiri } & Waktu & \multicolumn{1}{c|}{ Tangan Kanan } & Waktu \\
\cline { 2 - 4 } \cline { 3 - 4 } & (detik) & & (detik) \\
\hline Menunggu & 12.3 & Menjangkau Tube & 3.4 \\
\hline & & Meletakkan Tube Di Meja Check & 8.9 \\
\hline Total & 12.3 & Total & 12.3 \\
\hline Sub Total 5pcs & 61.5 & Sub Total 5pcs & 61.5 \\
\hline Memegang Tube & 3 & Mengambil Kuas & 3.7 \\
\hline \multicolumn{1}{|c|}{ Menunggu } & 20.4 & Mengoles Kuas Ke Air Sabun & 14.7 \\
\cline { 3 - 4 } & 3 & Memoles Tube & 3 \\
\hline Memutar Tube & 23.1 & Meraba Tube/Inspeksi & 23.1 \\
\hline Menunggu & 4.7 & Menunggu & 4.7 \\
\hline Melepas Cup & 6 & Meletakkan Tube & 60.2 \\
\hline Menunggu & 60.2 & & 301 \\
\hline Total & 301 & & 362.5 \\
\hline Sub Total 5pcs & 362.5 & & 5 Pcs \\
\hline \hline Total Waktu Tiap Siklus & 5 Pcs & & \\
\hline Jumlah Pcs Tiap Siklus & & & \\
\hline Sumber: Data Pengam & & \\
\hline
\end{tabular}

Sumber: Data Pengamatan

Tabel 4 PTKTK Vacuum dan Labeling

\begin{tabular}{|c|c|c|c|}
\hline Tangan Kiri & $\begin{array}{l}\text { Waktu } \\
\text { (detik) }\end{array}$ & Tangan Kanan & $\begin{array}{l}\text { Waktu } \\
\text { (detik) }\end{array}$ \\
\hline \multirow{4}{*}{ Menunggu } & \multirow{4}{*}{19.4} & Menjangkau Tube & 1.8 \\
\hline & & Memindahkan Ke Lori & \\
\hline & & Mendorong Lori Ke Meja Vakum & 9.2 \\
\hline & & Menjangkau Tube & \\
\hline Memegang Tube & 2.9 & Meletakkan Tube Ke Meja Vakum & 2.9 \\
\hline Memegang Valve & 1.6 & Memasukan Valve Ke Lubang Vak & 1.6 \\
\hline Sub Total & 23.9 & Sub Total & 23.9 \\
\hline Sub Total x 5 Tube & 119.5 & Sub Total x 5 Tube & 119.5 \\
\hline \multirow{4}{*}{ Menunggu } & \multirow{4}{*}{18.6} & Menekan Valve & 13.5 \\
\hline & & Memasukan Inside Core Kedalam & 2.1 \\
\hline & & \begin{tabular}{|l|} 
Menekan Tombol Airjet \\
\end{tabular} & 1.5 \\
\hline & & Memasukan Ke Lubang Vakum & 1.5 \\
\hline Sub Total & 18.6 & Sub Total & 18.6 \\
\hline Sub Total $\times 5$ Tube & 93 & Sub Total x 5 Tube & 93 \\
\hline Mengambil Cup & 2.9 & Menunggu & 2.9 \\
\hline Memutar Cup & 3.4 & Menunggu & 3.4 \\
\hline \multirow{3}{*}{ Menunggu } & \multirow{3}{*}{25.6} & Labelling & 2.1 \\
\hline & & \begin{tabular}{|l} 
Memindahkan Tube Ke Lori \\
\end{tabular} & 10 \\
\hline & & Mengantarkan Ke Booking Storage & 13.5 \\
\hline Sub Total & 31.9 & Sub Total & 31.9 \\
\hline Sub Total x 5 Tube & 159.5 & Sub Total $x 5$ Tube & 159.5 \\
\hline Total Waktu Tiap Siklus & 372 & & 607 \\
\hline Jumlah Pcs Tiap Siklus & $5 \mathrm{Pcs}$ & & 5 Pcs \\
\hline
\end{tabular}

Sumber: Data Pengamatan 
Tabel 5 PTKTK Booking Tube

\begin{tabular}{|c|c|c|c|}
\hline \multirow{2}{*}{ Tangan Kiri } & Waktu & \multirow{2}{*}{ Tangan Kanan } & $\begin{array}{l}\text { Waktu } \\
\text { (detik) }\end{array}$ \\
\hline & (detik) & & (detik) \\
\hline Menunggu & 11 & Mengambil Tube Dari Storege & 11 \\
\hline Memegang Tube & 4.3 & Menjangkau Tube & 4.3 \\
\hline \multirow{4}{*}{ Menunggu } & \multirow{4}{*}{9} & Meletakkan Tube Ke Pallet & 1.6 \\
\hline & & Merapikan Tube & 2.2 \\
\hline & & Menekan Tube & 2.4 \\
\hline & & Pewarnaan/Cat Valve & 2.8 \\
\hline Sub Total & 24.3 & Sub Total & 24.3 \\
\hline Sub Total x 5 Tube & 121.5 & Sub Total x 5 Tube & 121.5 \\
\hline Total Waktu Tiap Siklus & 121.5 & & 121.5 \\
\hline Jumlah Pcs Tiap Siklus & $5 \mathrm{Pcs}$ & & $5 \mathrm{Pcs}$ \\
\hline
\end{tabular}

\section{3) Uji Keseragaman Data dan Uji Ke- cukupan Data}

Dari data pengamatan yang telah dikumpulkan maka dilanjutkan perhitungan untuk melihat keseragaman data, kecukupan data dan menghitung waktu siklus dari rata-rata waktu pengamatan. Berikut tabel menunjukan perhitungan dari setiap elemen kerja.

Tabel 6 Uji Keseragaman Data Operator Part \& Inflate Tube

\begin{tabular}{|c|c|c|c|}
\hline No. & X(Detik) & $\mathbf{X}^{\mathbf{2}}$ & $(\mathbf{X}-\overline{\boldsymbol{X}})^{\mathbf{2}}$ \\
\hline 1 & 288.0 & $82,944.0$ & 39.7 \\
\hline 2 & 295.0 & $87,025.0$ & 0.5 \\
\hline 3 & 292.0 & $85,264.0$ & 5.3 \\
\hline 4 & 293.0 & $85,849.0$ & 1.7 \\
\hline 5 & 294.0 & $86,436.0$ & 0.1 \\
\hline 6 & 292.0 & $85,264.0$ & 5.3 \\
\hline 7 & 291.0 & $84,681.0$ & 10.9 \\
\hline 8 & 293.0 & $85,849.0$ & 1.7 \\
\hline 9 & 297.0 & $88,209.0$ & 7.3 \\
\hline 10 & 299.0 & $89,401.0$ & 22.1 \\
\hline 11 & 299.0 & $89,401.0$ & 22.1 \\
\hline 12 & 299.0 & $89,401.0$ & 22.1 \\
\hline JUMLAH & $\mathbf{3 , 5 3 2 . 0}$ & $\mathbf{1 , 0 3 9 , 7 2 4 . 0}$ & $\mathbf{1 3 8 . 7}$ \\
\hline ( $\left.\sum \mathbf{x i}\right)^{2}$ & $\mathbf{1 2 , 4 7 5 , 0 2 4 . 0}$ & & \\
\hline $\bar{x}$ & 294.3 & & \\
\hline std deviasi & $\mathbf{1 2 . 6}$ & & \\
\hline BKA & $\mathbf{3 1 9 . 5}$ & & \\
\hline BKB & $\mathbf{2 6 9 . 1}$ & & \\
\hline
\end{tabular}

Sumber: Data Pengamatan

Tabel Uji 7 Keseragaman Data Inspection

\begin{tabular}{|c|c|c|c|}
\hline NO & $\mathbf{X}$ (Detik) & $\mathbf{X}^{\mathbf{2}}$ & $(\mathbf{X}-\overline{\boldsymbol{X}})^{\mathbf{2}}$ \\
\hline 1 & 302.5 & $91,506.3$ & 11.6 \\
\hline 2 & 303.4 & $92,051.6$ & 6.3 \\
\hline 3 & 303.2 & $91,930.2$ & 7.3 \\
\hline 4 & 306.8 & $94,126.2$ & 0.8 \\
\hline 5 & 306.5 & $93,942.3$ & 0.4 \\
\hline 6 & 306.5 & $93,942.3$ & 0.4 \\
\hline 7 & 308.8 & $95,357.4$ & 8.4 \\
\hline 8 & 306.6 & $94,003.6$ & 0.5 \\
\hline 9 & 309 & $95,481.0$ & 9.6 \\
\hline 10 & 308.3 & $95,048.9$ & 5.8 \\
\hline 11 & 304.6 & $92,781.2$ & 1.7 \\
\hline 12 & 304.6 & $92,781.2$ & 1.7 \\
\hline JUMLAH & $\mathbf{3 , 6 7 0 . 8}$ & $\mathbf{1 , 1 2 2 , 9 5 2 . 0}$ & $\mathbf{5 4 . 3}$ \\
\hline (2xi) & $\mathbf{1 3 , 4 7 4 , 7 7 2 . 6}$ & & \\
\hline $\bar{x}$ & $\mathbf{3 0 5 . 9}$ & & \\
\hline std deviasi & $\mathbf{4 . 9}$ & & \\
\hline BKA & $\mathbf{3 1 5 . 8}$ & & \\
\hline BKB & $\mathbf{2 9 6 . 0}$ & & \\
\hline
\end{tabular}

Sumber: Data Pengamatan
Tabel 8 Uji Keseragaman Data Vacuum \& Labelling

\begin{tabular}{|c|c|c|c|}
\hline NO & X(Detik) & $\mathbf{X}^{2}$ & $(\mathrm{X}-\bar{x})^{2}$ \\
\hline 1 & 296 & $87,616.0$ & 0.6 \\
\hline 2 & 294.7 & $86,848.1$ & 4.4 \\
\hline 3 & 297.9 & $88,744.4$ & 1.2 \\
\hline 4 & 294.7 & $86,848.1$ & 4.4 \\
\hline 5 & 301.3 & $90,781.7$ & 20.3 \\
\hline 6 & 296.8 & $88,090.2$ & 0.0 \\
\hline 7 & 298.2 & $88,923.2$ & 2.0 \\
\hline 8 & 296.2 & $87,734.4$ & 0.4 \\
\hline 9 & 299.5 & $89,700.3$ & 7.3 \\
\hline 10 & 296.2 & $87,734.4$ & 0.4 \\
\hline 11 & 293.9 & $86,377.2$ & 8.4 \\
\hline 12 & 296.3 & $87,793.7$ & 0.3 \\
\hline JUMLAH & $3,561.7$ & $1,057,191.8$ & 49.6 \\
\hline$\left(\sum x i\right)^{2}$ & $12,685,706.9$ & & \\
\hline $\bar{x}$ & 296.8 & & \\
\hline std deviasi & 4.5 & & \\
\hline BKA & 305.8 & & \\
\hline BKB & 287.8 & & \\
\hline
\end{tabular}

Sumber: Data Pengamatan

Tabel 9 Uji Keseragaman dan Kecukupan Data booking tube.

\begin{tabular}{|c|c|c|c|}
\hline NO & X(Detik) & $\mathbf{X}^{\mathbf{2}}$ & $(\mathbf{X}-\bar{x})^{\mathbf{2}}$ \\
\hline 1 & 95.3 & $9,082.1$ & 2.3 \\
\hline 2 & 93 & $8,649.0$ & 14.4 \\
\hline 3 & 94 & $8,836.0$ & 7.8 \\
\hline 4 & 98.8 & $9,761.4$ & 4.0 \\
\hline 5 & 98.8 & $9,761.4$ & 4.0 \\
\hline 6 & 95.8 & $9,177.6$ & 1.0 \\
\hline 7 & 99 & $9,801.0$ & 4.8 \\
\hline 8 & 99.3 & $9,860.5$ & 6.3 \\
\hline 9 & 99.3 & $9,860.5$ & 6.3 \\
\hline 10 & 95.8 & $9,177.6$ & 1.0 \\
\hline 11 & 95.8 & $9,177.6$ & 1.0 \\
\hline 12 & 96.5 & $9,312.3$ & 0.1 \\
\hline JUMLAH & $\mathbf{1 , 1 6 1 . 4}$ & $\mathbf{1 1 2 , 4 5 7 . 1}$ & $\mathbf{5 3 . 0}$ \\
\hline (2x) & $\mathbf{1 , 3 4 8 , 8 5 0 . 0}$ & & \\
\hline $\bar{x}$ & $\mathbf{9 6 . 8}$ & & \\
\hline std deviasi & $\mathbf{4 . 8}$ & & \\
\hline BKA & $\mathbf{1 0 6 . 4}$ & & \\
\hline BKB & $\mathbf{8 7 . 2}$ & & \\
\hline
\end{tabular}

Sumber: Data Pengamatan

\section{4). Penentuan Rating Factor (Faktor Penye- suaian)}

Dalam hal penentuan rating faktor $\mathrm{di}$ gunakan metode westinghouse yang mengarahkan penilaian pada empat faktor yang dianggap menentukan kewajaran atau ketidakwajaran dalam bekerja yaitu: keterampilan, usaha, kondisi kerja dan konsistensi. Setiap faktor terbagi kedalam kelas-kelas dengan nilainya masing-masing sebagai berikut:

1. Operator 1

Rating faktor operator 1 adalah

1 Keterampilan $=$ Average $(\mathrm{D})+0.00$

2 Usaha $=\operatorname{Good}(\mathrm{C} 2)+0.02$

3 Kondisi Kerja $=$ Average $(\mathrm{D})+0.00$

4 Konsistensi $=$ Average $(\mathrm{D})+0.00$

Total $=+0.02$

jadi $\mathrm{P}=1+0,02=1,02$

2. Operator 2

Rating faktor operator 2 adalah: 
1 Keterampilan $=\operatorname{Good}(\mathrm{C} 2)+0.03$

2 Usaha $=\operatorname{Good}(\mathrm{C} 2)+0.00$

3 Kondisi Kerja $=$ Average $(\mathrm{D})+0.00$

4 Konsistensi $=$ Average $(\mathrm{C})+0.00$

Total $=+0.03$

jadi $\mathrm{P}=1+0,03=1,03$

3. Operator 3

Rating faktor operator 3 adalah:

1 Keterampilan $=$ Average $(\mathrm{D})+0.00$

2 Usaha $=\operatorname{Good}(\mathrm{C} 2)+0.02$

3 Kondisi Kerja $=$ Average $(\mathrm{D})+0.00$

4 Konsistensi $=\operatorname{Good}(\mathrm{C})+0.01$

Total $=+0.03$

jadi $\mathrm{P}=1+0,03=1,03$

4. Operator 4

Rating faktor operator 4 adalah

1 Keterampilan $=$ Average $(\mathrm{D})+0.00$

2 Usaha $=\operatorname{Good}(\mathrm{C} 2)+0.02$

3 Kondisi Kerja $=$ Average $(\mathrm{D})+0.00$

4 Konsistensi $=$ Average $(\mathrm{D})+0.00$

Total $=+0.02$

jadi $\mathrm{P}=1+0,02=1,02$

\section{5) Penentuan Allowance}

Tabel 10. Allowance Operator

\begin{tabular}{|c|c|c|c|c|c|}
\hline \multirow[b]{2}{*}{ Faktor } & \multirow[b]{2}{*}{$\begin{array}{c}\text { Referen } \\
\text { si }\end{array}$} & \multicolumn{4}{|c|}{$\%$ Allowance } \\
\hline & & \begin{tabular}{|c|} 
Opera \\
tor 1
\end{tabular} & \begin{tabular}{|c|} 
Opera \\
tor 2
\end{tabular} & $\begin{array}{c}\text { Operat } \\
\text { or } 3\end{array}$ & $\begin{array}{c}\text { Operat } \\
\text { or } 4\end{array}$ \\
\hline Tenaga yang dikeluarkan & $0-6 \%$ & 6 & 6 & 6 & 6 \\
\hline Sikap kerja & $0-1 \%$ & 1 & 2.5 & 2.5 & 1 \\
\hline Gerakan kerja & 0 & 0 & 0 & 0 & 0 \\
\hline Kelelahan mata & $0-19 \%$ & 10 & 12 & 12 & 9 \\
\hline Keadaan temperatur & $5-40 \%$ & 5 & 5 & 5 & 5 \\
\hline Kebutuhan pribadi & $2-2,5 \%$ & 2 & 2 & 2 & 2 \\
\hline Hambatan yang tidak dapat dihindarkan & $0-6 \%$ & 4 & 6 & 4 & 4 \\
\hline \multicolumn{2}{|l|}{ Total } & 28 & 33.5 & 31.5 & 27 \\
\hline
\end{tabular}

Sumber: Data Pengamatan

\section{6) Waktu Normal}

Menggunakan persamaan $\mathrm{Wn}=\mathrm{Ws} \times \mathrm{p}$ untuk mencari waktu normal dengan menghitung waktu siklus (Ws) dari rata- rata pengamatan yang telah dilakukan menggunakan rumus (Rating Faktor Westinghouse) +1 (kerja normal) maka diperoleh hasil:

Tabel 11 Perhitungan Waktu Normal

\begin{tabular}{|l|c|c|c|c|}
\hline \multirow{2}{*}{ Elemen Kerja } & $\begin{array}{c}\text { Waktu } \\
\text { Siklus }\end{array}$ & \multirow{2}{*}{$\begin{array}{c}\text { Rating } \\
\text { Faktor }\end{array}$} & $\begin{array}{c}\text { Waktu } \\
\text { Normal }\end{array}$ & $\begin{array}{c}\text { Pembulatan } \\
\text { Waktu } \\
\text { Normal }\end{array}$ \\
\cline { 2 - 2 } & (detik) & & (detik) & (detik) \\
\hline Part Tube Dan Inflate Tub & 294.3 & 1.02 & 300.19 & 300 \\
\hline Inspection & 305.9 & 1.03 & 315.08 & 315 \\
\hline Vacuum Dan Labelling & 296.8 & 1.03 & 305.7 & 306 \\
\hline Booking tube & 96.8 & 1.02 & 98.74 & 99 \\
\hline
\end{tabular}

Sumber: Data Pengamatan

\section{7) Waktu Baku}

Perhitungan waktu standar dilakukan untuk mengetahui seberapa besar waktu yang dibutuhkan pekerja dalam melakukan proses kerja berdasarkan rating faktor dan allowance yang dimiliki oleh operator tersebut.Dengan demikian waktu standar yang dihasilkan dalam pengamatan yang telah dilakukan dengan rumus $\mathrm{Wb}=\mathrm{Wn} \times(1+\mathrm{i})$, maka diperoleh hasil:

Tabel 12 Waktu Standar

\begin{tabular}{|l|c|c|c|c|}
\hline \multicolumn{1}{|c|}{ Elemen Kerja } & $\begin{array}{c}\text { Waktu } \\
\text { Normal } \\
\text { (detik) }\end{array}$ & $\begin{array}{c}\text { Allow } \\
\text { ance }\end{array}$ & $\begin{array}{c}\text { Waktu } \\
\text { Standar } \\
\text { (detik) }\end{array}$ & $\begin{array}{c}\text { Pembul } \\
\text { atan } \\
\text { (detik) }\end{array}$ \\
\hline Part Tube Dan Inflate Tube & 300 & 28 & 416.67 & 417 \\
\hline Inspection & 315 & 33.5 & 473.68 & 474 \\
\hline Vacuum Dan Labelling & 306 & 31.5 & 446.71 & 447 \\
\hline Booking & 99 & 27 & 135.61 & 136 \\
\hline
\end{tabular}

Sumber: Data Pengamatan

\section{8) Diagram Fishbone}

Analisa selanjutnya untuk identifikasi penyebab-penyebab yang mungkin timbul dari permasalahan dapat dijelaskan dengan gambar berikut:

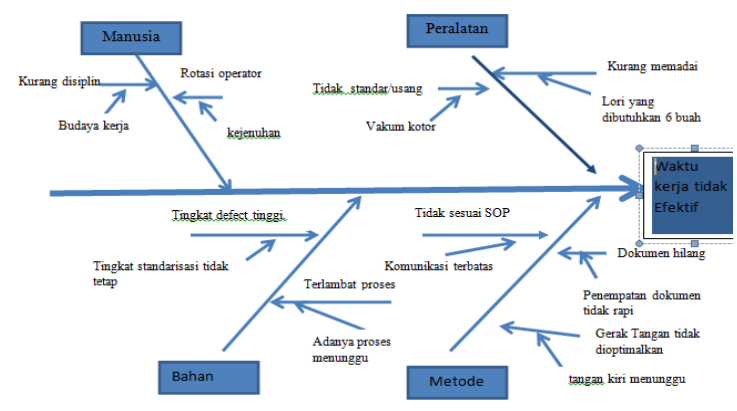

Gambar 2 Diagram Fishbond

Tabel 13 Rencana Penanggulangan faktor kerja yang tidak efektif

\begin{tabular}{|c|c|c|}
\hline Faktor Yang Diamati & Masalah Yang Terjadi & Rekomendasi Yang Diberikan \\
\hline \multirow{2}{*}{ Manusia } & a.Kurangnya disiplin & \begin{tabular}{|l|}
$\begin{array}{l}\text { Melakukan penegasan dan sanksi } \\
\text { administratif atas ketidak disiplinan }\end{array}$ \\
\end{tabular} \\
\hline & b.Rotasi operator & $\begin{array}{l}\text { Memberikan kesempatan rotasi operator } \\
\text { untuk menghindari kejenuhan }\end{array}$ \\
\hline \multirow[t]{2}{*}{ Bahan/tube } & a.Tingkat defect tinggi & $\begin{array}{l}\text { Dilakukan pengontrolan dan inspeksi } \\
\text { khusus tiap per sampel defect dengan } \\
\text { melakukan penegasan ke unit produksi } \\
\text { untuk mengehentikan bahan yang } \\
\text { berpotensi cacat dengan standarisasi yang } \\
\text { paten. }\end{array}$ \\
\hline & b. Terlambatya proses & $\begin{array}{l}\text {-Pengeliminasian proses yang tidak } \\
\text { seharusnya dilakukan dan penjadwalan } \\
\text { yang terstruktur pendistribusian tube }\end{array}$ \\
\hline \multirow{3}{*}{ Metode } & a.Tidak sesuai $S O P$ & $\begin{array}{l}\begin{array}{l}\text { Pembuatan target disesaikan dengan } \\
\text { waktu baku yang dilakukan operator } \\
\text { dalam bekerja }\end{array} \\
\end{array}$ \\
\hline & \multirow{2}{*}{ b.Dokumen hilang, } & - Dibuatkan sekat pemisah antar dokumen \\
\hline & & $\begin{array}{l}\text {-Dibuatkan marking dan tempat khusus } \\
\text { untuk tiap dokumen }\end{array}$ \\
\hline \multirow{2}{*}{ Peralatan } & a.Tidak standar/usang. & \begin{tabular}{|l|}
-Peremajaan peralatan dan mesin \\
- Pengontrolan dan perawatan mesin \\
secara berkala
\end{tabular} \\
\hline & b.Kurang memadai & $\begin{array}{l}\text { Pengadaan peralatan yang dibutuhkan } 6 \\
\text { buah disesuaikan dengan kebuttuhan agar } \\
\text { produktifitas oem tube lancar }\end{array}$ \\
\hline
\end{tabular}

Sumber: Data Pengamatan

\section{Analisa dan Pembahasan}

1) Analisa Gerak dan Waktu Kegiatan Part dan Inflate Tube

Gerakan yang terjadi pada proses part dan inflate tube memerlukan waktu 417 detik 
yang dihasilkan dari lamanya pasang part dan inflate tube, pada saat pengambilan part dibutuhkan waktu yang mencari dan memilah part untuk dipasang di valve membuat waktu yang terbuang, mesin inflate yang sering macet membutuhkan waktu untuk memperbaiki dalam penekanan tombol sehingga mengurangi waktu efektifitas kerja. Dari gerakan kerja bisa disederhanakan lagi dengan penyederhanaan cara kerja dengan menggerakkan tangan kiri saat memilah part, pengarahan part, pemutaran nut dan pemutaran cup. Sehingga perlu pengukuran ulang waktu dan gerakan yang tidak efektif. Diharapkan dengan penyederhanaan cara kerja bisa mengurangi waktu tunggu tangan kiri dan hasil kegiatan tersebut digabungkan mendapatkan rata rata total waktu proses yang sebelumnya 294,2 detik menjadi 266,9 detik.

Tabel 14 Evaluasi pasang part dan inflate tube (setelah perbaikan)

\begin{tabular}{|c|c|c|c|c|c|c|c|c|c|c|c|c|c|}
\hline \multicolumn{14}{|l|}{ Nama Operator : MARALWI } \\
\hline \multicolumn{14}{|l|}{ Bagian :OEM Final Inspection } \\
\hline \multicolumn{14}{|c|}{ Jobdesk: Pasang Part Dan Inflate Tube } \\
\hline \multicolumn{14}{|c|}{ Mulai : 07.00 Selesai: 15.00 Output Yang Dihasilkan Per Menit: 5 Tube } \\
\hline Langkah & \multicolumn{12}{|c|}{ Banyaknya Pengukuran (Detik) } & \\
\hline Merapikan Tube & 8.5 & 8.8 & 8.3 & 8.0 & 8.5 & 9.0 & 9.3 & 9.0 & 8.8 & 8.5 & 8.8 & 9.0 & \\
\hline Menarik Valve & 5.3 & 6.5 & 5.8 & 6.8 & 6.5 & 5.5 & 5.8 & 6.8 & 6.3 & 6.5 & 7.3 & 6.5 & \\
\hline Mengambil Part & 11.0 & 11.3 & 13.0 & 11.0 & 10.8 & 12.0 & 11.5 & 11.5 & 11.0 & 12.3 & 313.0 & 13.0 & \\
\hline Memilah Part & & 5.8 & 4.4 & 3.9 & 4.2 & 4.4 & 4.7 & 4.4 & 5.1 & 5.4 & 4.7 & 4.9 & \\
\hline Mengarahkan part & 4.9 & 5.1 & 5.4 & 4.9 & 5.6 & 4.7 & 4.4 & 4.7 & 5.8 & 5.4 & 5.1 & 4.7 & \\
\hline Memasang Part & 26.5 & 27.3 & 26.6 & 28.2 & 26.8 & \begin{tabular}{|c|c|}
8 & 27.7 \\
\end{tabular} & 26.8 & 27.9 & 28.4 & 28.9 & 27.5 & 27.5 & \\
\hline \begin{tabular}{|l|} 
Memutar Nut \\
\end{tabular} & 10.2 & 9.8 & 10.4 & 10.4 & 10.2 & 210 & 10.2 & 9.3 & 10.4 & 9.7 & 10.4 & 10.9 & \\
\hline Mengambil Selang Inflate & 8.5 & 8.8 & 8.3 & 9.3 & 9.8 & 8.5 & \begin{tabular}{|l|}
9.0 \\
\end{tabular} & 9.5 & 9.0 & 9.3 & 9.0 & 9.8 & \\
\hline Menekan Tombol Inflate & 142.0 & \begin{tabular}{|l|l|}
143.0 \\
\end{tabular} & 142.0 & \begin{tabular}{|l|l|}
143.0 \\
\end{tabular} & 143.0 & $\begin{array}{l}0142.0 \\
\end{array}$ & \begin{tabular}{|l|l|}
142.0 \\
\end{tabular} & 142.0 & 142.0 & .0142 .0 & 143.0 & \begin{tabular}{|l|l|}
142.0 \\
\end{tabular} & 142. \\
\hline \begin{tabular}{|l|} 
Mengambil Cup \\
\end{tabular} & 11.3 & 11.0 & 11.5 & \begin{tabular}{|l|}
11.5 \\
\end{tabular} & 12.3 & \begin{tabular}{|l|l|}
311.5 \\
\end{tabular} & \begin{tabular}{|l|}
11.5 \\
\end{tabular} & 11.8 & 12.0 & \begin{tabular}{ll|}
.0 & 11.0 \\
\end{tabular} & 11.5 & \begin{tabular}{|l|}
12.3 \\
\end{tabular} & \\
\hline Memutar Cup & 7 & 7.4 & 7.3 & 7.2 & 7 & $\begin{array}{ll}7.3 \\
7\end{array}$ & 7.3 & 7.2 & 7.8 & \begin{tabular}{l|l|}
.8 & 7.8 \\
\end{tabular} & \begin{tabular}{|l|}
3.4 \\
\end{tabular} & 7.4 & \\
\hline Menggulirkan tube & 22.0 & 22.3 & 21.8 & 22.3 & 22.3 & \begin{tabular}{|l|l|}
3 & 21.8 \\
\end{tabular} & 22.0 & 22.0 & 22.3 & \begin{tabular}{|l|l|}
3 & 23.3 \\
\end{tabular} & 24.3 & \begin{tabular}{|l|}
22.8 \\
\end{tabular} & \\
\hline Tota & 261.2 & 267.0 & 264.7 & 266.4 & 267.0 & \begin{tabular}{|l|}
064.4 \\
\end{tabular} & 264.4 & 266.1 & & \begin{tabular}{l|l|}
8270.1 \\
\end{tabular} & 271.9 & 270.8 & 266. \\
\hline
\end{tabular}

Sumber: Data Pengamatan

Keterangan

$=$ kegiatan yang dapat dihilangkan

2) Analisa Gerak dan Waktu Kegiatan Inspection

Tabel 15 Pengamatan Inspection (setelah perbaikan)

\begin{tabular}{|c|c|c|c|c|c|c|c|c|c|c|c|c|c|c|}
\hline \\
\hline Bagian:OEM Final Inspection & & & & & & & & & & & & & & \\
\hline Jobdesk : INSPECTION & & & & & & & & & & & & & & \\
\hline Mual:07.00 Selesai: 15.00 & & & & & & & & & & & & & & \\
\hline Langkah Kerja & & & & & & anyakn & ya Penz & gukura & n (Deti) & & & & & Rata- \\
\hline Menjangkau Tube & 13.5 & & & 12 & & 13.5 & \begin{tabular}{|c|}
13.5 \\
\end{tabular} & 14 & 13.5 & 14.5 & 14.5 & 12.5 & 14.5 & 13.5 \\
\hline Meletakkan Tube Di Meja Check & 34.2 & 3 & & 35.5 & 35.5 & 36.1 & 35.5 & 35.5 & 35.7 & 36.1 & 35.7 & 35.8 & 35. & 35.5 \\
\hline Mengambil Kuas & 12. & & & 11.5 & 12 & 11.5 & 12.5 & 12 & 11.7 & 11.8 & 12.5 & 11.7 & 11. & 11.8 \\
\hline \begin{tabular}{|l} 
Mengoles Kuas Ke Air Sabun \\
\end{tabular} & 22. & 2 & & 22.5 & 23 & 22.5 & 22.8 & 22.5 & 22.5 & 23.5 & 22.9 & 22.5 & 22. & 22.6 \\
\hline \begin{tabular}{|l|} 
Memoles Tube \\
\end{tabular} & 58. & 55 & & 57.5 & 58 & 58.8 & \begin{tabular}{|l|}
58.9 \\
\end{tabular} & 59.2 & 59.4 & 58.5 & 58.9 & 59.1 & 58. & 58.7 \\
\hline Memutar Tube & 10. & 1 & & 12 & 12.5 & 12.1 & 11.5 & 12.2 & 11.5 & 12.5 & 12.5 & 11.5 & 11. & \begin{tabular}{|l|l|}
511.8 \\
\end{tabular} \\
\hline Inspeksi & 10 & 10 & & 09.2 & 109.4 & \begin{tabular}{|l|l|}
108.8 \\
\end{tabular} & 109.8 & 109.5 & \begin{tabular}{|l|l|}
109.5 \\
\end{tabular} & \begin{tabular}{|l|}
108.7 \\
\end{tabular} & 108.9 & 108.8 & 109.2 & 92.5 \\
\hline Melepas Cup & 18. & & & 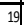 & 19.5 & 19.5 & 18.5 & 19.5 & 18.3 & 18.5 & 18.5 & 19 & & 18.8 \\
\hline \begin{tabular}{|l} 
Meletakkan Tube \\
\end{tabular} & 24. & & 24 & 24 & 23.9 & 23.7 & 23.5 & 24.4. & 24.5 & 24.5 & 23.9 & 23.7 & 23.4 .5130 & 24 \\
\hline Tot: & 302.5 & 303 & & 3.2 & 306.8 & 306.5 & 306.5 & 308.8 & 3066 & 308.6 & & & 304.6 & 289.3 \\
\hline
\end{tabular}

Sumber: Data Pengamatan

Inspection ini termasuk langkah kerja untuk menjamin bahwa obyek telah memenuhi persyaratan kualitas yang ditetapkan. Gerakan kerja dilaksanakan dengan pengecekan secara rutin oleh operator selama proses kerja berlangung. Elemen dapat berupa gerakan melihat seperti memerikasa defect, meraba seperti memeriksa kahalusan permukaan tube dan lain-lain aktivitas yang prinsipnya memeriksa obyek kerja untuk dibandingkan dengan standard yang lain. Waktu yang di-perlukan untuk kegiatan memeriksa ini akan bergantung kepada kecepatan operator menemukan perbedaan antara obyek dengan performans standard yang dibandingkan. Elemen kerja ini termasuk dalam efektif dan tidak dapat dihindari.

\section{3) Analisa Gerak dan Waktu Kegiatan Vacuum dan labeling}

Tabel 16 Pengamatan Vacuum, Labeling (setelah perbaikan)

\begin{tabular}{|c|c|c|c|c|c|c|c|c|c|c|c|c|c|}
\hline \multicolumn{14}{|l|}{\begin{tabular}{|l|l|l|} 
Nama Operator : ENDANG JULIAWAN \\
\end{tabular}} \\
\hline \multicolumn{14}{|l|}{ Bagian:OEM Final Inspection } \\
\hline \multirow{2}{*}{\multicolumn{14}{|c|}{ Jobdesk:VAKUM \& Labelling }} \\
\hline \multicolumn{7}{|l|}{ Mulai :07.00 Selesaxi: 15.00 } & & & & & & & \\
\hline Langkah Kerja & \multicolumn{12}{|c|}{ Banyaknya Pengukuran (Detik) } & \\
\hline Menjangkau Tube & 7.0 & & & 7.3 & 7.8 & & & & & $\begin{array}{l}8.0 \\
8.0 \\
-10\end{array}$ & $\begin{array}{l}0.1 .8 \\
0\end{array}$ & 7.87 .0 & \\
\hline Memindahkan Ke Lori & 26.8 & 28.0 & 27.0 & 26.8 & 27.8 & 27.3 & 28.0 & 26.8 & 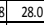 & \begin{tabular}{l|l}
0 & 27.3 \\
0 &
\end{tabular} & \begin{tabular}{c|c}
3 & 27.0 \\
\end{tabular} & $\begin{array}{l}7.0 \\
27.3 \\
\end{array}$ & 27.3 \\
\hline Mendorong Lori Ke N & 36.5 & 37.3 & 36.8 & 36.5 & 38.0 & 36.3 & 36.0 & 36.8 & \begin{tabular}{l|l}
837.8 \\
\end{tabular} & \begin{tabular}{l|l}
837.0 \\
\end{tabular} & $\begin{array}{ll}0 & 37.0 \\
\end{array}$ & 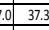 & 36.9 \\
\hline Menjangkau Tube & 6.5 & 5.5 & 6.0 & 6.3 & 5.5 & 6.5 & 7.8 & 5.8 & \begin{tabular}{l|l}
8 & 6.5 \\
\end{tabular} & $\begin{array}{l}5.6 .3 \\
5.30\end{array}$ & $\begin{array}{l}35.8 \\
3 \quad r a t\end{array}$ & 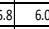 & 6.2 \\
\hline Meletakkan Tube Ke Meja Vakum & 10.8 & 11.3 & 11.0 & 11.0 & 11.8 & 11.3 & 10.5 & 12.0 & \begin{tabular}{l|l}
0 & 12.0 \\
\end{tabular} & & & 1.512 .3 & \\
\hline \multicolumn{14}{|l|}{ Memasukan Valve Ke Lubang Vakum } \\
\hline Menekan Valve & 53.3 & 52.5 & 56.8 & 57.0 & 54.3 & 53.3. & 54.0 & 53.8 & 53.3 & 54.5 & 52.8 & 2.853 .5 & 54.1 \\
\hline Memasukan Inside Core Ke Valve & 9.0 & 8.0 & 7.8 & 8.0 & 8.5 & 8.8 & 8.5 & 8.0 & 8.8 & 8.5 & 8.0 & $\begin{array}{l}3.07 .8 \\
.07-30\end{array}$ & 7.8 \\
\hline \begin{tabular}{|l|} 
Menekan Tombol Airjet \\
\end{tabular} & 5.5 & 6.0 & 5.3 & 5.8 & 8.3 & 6.5 & 6.0 & 6.0 & 6.3 & 5.8 & 5.3 & 5.3 & 5.5 \\
\hline Memasukan valve Ke Lubang Vakum & 5.8 & 5.3 & 6.0 & 6.0 & 5.8 & 5.3 & 6.0 & 6.3 & 5.8 & $\begin{array}{l}8.5 .5 \\
\end{array}$ & 5.8 & 5.8 & .0 \\
\hline Mengambil Cup & 11.5 & 11.5 & 11.5 & 11.3 & 11.8 & 11.5 & 11.8 & 11.5 & 11.8 & \begin{tabular}{l|l}
8 & 10.5 \\
\end{tabular} & 10.5 & 11.8 & \\
\hline Memutar Cup & 13.8 & 13.3 & 14.0 & 8.8 & 14.0 & 14.0 & 14.3 & 13.5 & 13.3 & \begin{tabular}{l|l}
33 & 14.0 \\
\end{tabular} & $\begin{array}{ll}.0 & 14.3 \\
\end{array}$ & 4.3. & 4.0 \\
\hline Labelling & 9.0 & 8.3 & 8.3 & 8.3 & 8.5 & 8.3 & 8.5 & 8.8 & 9.0 & \begin{tabular}{l|l}
0 & 8.5 \\
0
\end{tabular} & 8.5 & 3.5 & 3.0 \\
\hline Memindahkan Tube Ke Lori & 39.3 & 41.5 & 411.3 & 41.8 & 39.8 & 39.5 & 39.3 & 39.5 & 39.5 & \begin{tabular}{l|l}
5 & 39.8 \\
\end{tabular} & \begin{tabular}{l|l|}
8 & 39.3 \\
\end{tabular} & 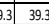 & 40.0 \\
\hline Mengantarkan Ke Booking Tube & 54.5 & 54.3 & 53.5 & 53.5 & 53.3 & 54.3 & 54.3 & 53.5 & 53.8 & $\begin{array}{l}853.0 \\
53 x-0\end{array}$ & \begin{tabular}{l|l|}
$: 0$ & 54.0 \\
\end{tabular} & $\begin{array}{ll}4.0 & 53.8\end{array}$ & 3.8 \\
\hline & 289.3 & & & 288.2 & 295.1 & 290.0 & & & & & & 7.4289 .6 & $\begin{array}{l}9.6 \\
290.4 \\
\end{array}$ \\
\hline
\end{tabular}
Sumber: Data Pengamatan

Kegiatan memasukan valve ke lubang Vacuum atau biasa disebut pengempesan/ flatting sebaiknya cukup dilakukan satu kali saja. Karena sama saja prosesnya setelah memasukan inside core. Sehingga bisa memaksimalkan waktu kerja. Dan bisa didapat waktu standar sebelumnya rata-rata total waktu proses 296,6 detik menjadi 290,4 detik.

\section{4) Analisa Gerak dan Waktu Kegiatan booking}

Tabel 17 Pengamatan Booking tube

\begin{tabular}{|c|c|c|c|c|c|c|c|c|c|c|c|c|c|}
\hline \multicolumn{14}{|l|}{ Nama Operator : AJID } \\
\hline \multicolumn{14}{|l|}{ Bagan :OEM Final Inspection } \\
\hline \multicolumn{14}{|c|}{\begin{tabular}{|l} 
Jobdesk :Booking Tube \\
\end{tabular}} \\
\hline \multicolumn{14}{|l|}{ Mulai:07.00 Selesai: 15.00} \\
\hline Langkah Kerja & \multicolumn{12}{|c|}{ Banyaknya Pengukuran (Detik) } & $\begin{array}{l}\text { Rata- } \\
\text { Rata }\end{array}$ \\
\hline \multicolumn{14}{|c|}{ Mengambil Tube Dari Storege Sementara } \\
\hline Menjangkau Tube & 16.8 & 16.5 & 15.3 & 18.3 & 19.5 & 16.5 & 17.3 & 18.0 & 17.8 & 16.5 & 16.8 & 17.0 & 17.2 \\
\hline Meletakkan Tube Ke Pallet & 5.5 & 6.0 & 6.0 & 6.3 & 6.3 & 6.3 & 6.5 & 7.0 & 6.8 & 5.5 & 6.3 & 6.3 & 6.2 \\
\hline Merapikan Tube & 8.8 & 9.0 & 8.3 & 9.5 & 9.5 & 8.8 & 9.3 & 8.8 & 9.0 & 9.5 & 8.0 & 8.3 & 8.9 \\
\hline Menekan Tube & 9.8 & 9.8 & 9.0 & 8.8 & 9.0 & 9.0 & 9.8 & 10.3 & 10.5 & 9.3 & 9.5 & 8.3 & 9.4 \\
\hline \multirow[t]{2}{*}{\begin{tabular}{|l} 
Pewarnaan/Cat Valve \\
\end{tabular}} & 11.3 & 8.3 & 11.0 & 11.3 & 11.5 & 11.5 & 12.0 & 12.3 & 11.5 & 11.8 & 11.0 & 12.0 & 11.3 \\
\hline & 52.1 & 49.5 & 49.6 & 54.1 & 55.8 & 52.0 & 54.8 & 56.4 & 55.6 & 52.6 & 51.6 & 51.8 & 53.0 \\
\hline
\end{tabular}

Sumber: Data Pengamatan

Kegiatan ini menunjukkan situasi yang tidak efektif yang dilakukan oleh operator 
(menunggu tube di distribusikan ke storage sementara, dengan mondar mandir hanya memastikan tube sudah divacuum \& labeling) sehingga perbaikan atau penanggulangan yang perlu dilakukan lebih ditujukan dengan merubah proses operasi kerjanya yaitu setelah tube divacuum dan labeling, di pindahkan ke Lori. Tube sebaiknya diarahkan langsung ke booking tube dengan ini bisa menghemat waktu proses kerja. Sebelumnya rata rata total waktu proses 96.8 detik menjadi 53 detik.

\section{5) Peta Tangan Kiri dan Tangan Kanan (PTKTK)}

Pengukuran waktu dilakukan dengan mengamati peta tangan kiri dan tangan kanan setiap gerakan tangan. Berikut ini peta tangan kiri dan tangan kanan (PTKTK) setiap elemen yang menggunakan gerakan tangan.

Tabel 18 PTKTK Part Tube dan Inflate

\begin{tabular}{|l|c|l|c|}
\hline \multicolumn{1}{|c|}{ Tangan Kiri } & Waktu & \multirow{2}{*}{ Tangan Kanan } & Waktu \\
\cline { 2 - 2 } & (detik) & & (detik) \\
\hline Memegang Ban & 2.2 & Memegang Tube & 2.2 \\
\hline Menarik Tube & 1.6 & Menarik Tube & 1.6 \\
\hline Sub Total & 3.8 & Sub Total & 3.8 \\
\hline & & & \\
\hline Menunggu & 3 & Mengambil Part & 3 \\
\hline Memilah Part & 1.2 & Memilah Part & 1.2 \\
\hline Mengarahkan Part & 1.3 & Mengarahkan Part & 1.3 \\
\hline Memasang Part & 6.9 & Memasang Part & 6.9 \\
\hline Memutar Nut & 2.5 & Memutar Nut & 2.5 \\
\hline Sub Total & 14.9 & Sub Total & 14.9 \\
\hline Sub Total x 5 Tube & $\mathbf{7 4 . 5}$ & Sub Total x 5 Tube & 74.5 \\
\hline & & & \\
\hline Menunggu & 2.3 & Mengambil Selang Infl: & 2.3 \\
\hline Memegang Valve & 35.6 & Menekan Tombol Infla & 35.6 \\
\hline Mengambil Cup & 2.9 & Melepas Tombol & 2.9 \\
\hline Memutar Cup & 1.8 & memutar cup & 1.8 \\
\hline Menunggu & 5.6 & Menggulirkan Tube & 5.6 \\
\hline Sub Total & $\mathbf{4 8 . 2}$ & Sub Total & 48.2 \\
\hline Sub Total x 5 Tube & $\mathbf{2 4 1}$ & Sub Total x 5 Tube & 241 \\
\hline Total Waktu Tiap Siklus & $\mathbf{3 1 9 . 3}$ & & 319.3 \\
\hline Jumlah Pcs Tiap Siklus & 5 Pcs & & 5 Pcs \\
\hline Sumber: Data Pengam & & & \\
\hline
\end{tabular}

Sumber: Data Pengamatan

Keterangan:

= kegiatan yang dapat digabungkan.

Dengan cara mengaktifkan tangan kiri yang menganggur sehingga butuh penggabungan kerja tangan kanan dan tangan kiri. Dengan menggerakkan kedua tangan bisa menghemat waktu baku/standar dan mengurangi waktu menunggu serta memaksimalkan waktu agar efektif yaitu menggabungkan proses Memilah /memilih part, mengarahkan part, memasang part, dan memutar nut yang memaksimalkan kerja tangan kiri.sehingga dari Tabel PTKTK didapatkan hasil sub total waktu x 5 tube dari kegiatan Memilah/memilih part, mengarahkan part, memasang part sebelumnya 99,5 detik menjadi 74,5 detik dan sub total waktu x 5 tube dari kegiatan memutar cup sebelumnya 250,5 detik menjadi 241 detik.

Tabel 19 PTKTK Inspection

\begin{tabular}{|c|c|c|c|}
\hline \multirow{2}{*}{ Tangan Kiri } & Waktu & \multirow{2}{*}{ Tangan Kanan } & Waktu \\
\hline & (detik) & & (detik) \\
\hline \multirow{2}{*}{ Menunggu } & \multirow{2}{*}{12.3} & Menjangkau Tube & 3.4 \\
\hline & & Meletakkan Tube Di Meja Check & 8.9 \\
\hline Total & 12.3 & Total & 12.3 \\
\hline Sub Total 5pcs & 61.5 & Sub Total 5pcs & 61.5 \\
\hline Memegang Tube & 3 & Mengambil Kuas & 3 \\
\hline \multirow{2}{*}{ Menunggu } & \multirow{2}{*}{20.4} & Mengoles Kuas Ke Air Sabun & 5.7 \\
\hline & & Memoles Tube & 14.7 \\
\hline Memutar Tube & 3 & Menunggu & 3 \\
\hline Memegang tube & 23.1 & Meraba Tube/Inspeksi & 23.1 \\
\hline Melepas Cup & 4.7 & Menunggu & 4.7 \\
\hline Memegang tube & 6 & Meletakkan Tube & 6 \\
\hline Total & 60.2 & & 60.2 \\
\hline Sub Total 5pcs & 301 & & 301 \\
\hline Total Waktu Tiap Siklus & 362.5 & & 362.5 \\
\hline Jumlah Pcs Tiap Siklus & 5 Pcs & & $5 \mathrm{Pcs}$ \\
\hline
\end{tabular}

Inspection ini termasuk langkah kerja untuk menjamin bahwa obyek telah memenuhi persyaratan kualitas yang ditetapkan. Gerakan kerja dilaksanakan dengan pengecekan secara rutin oleh operator selama proses kerja berlangung. Elemen dapat berupa gerakan melihat seperti memerikasa defect, meraba seperti memeriksa kahalusan permukaan tube dan lain-lain aktivitas yang prinsipnya memeriksa obyek kerja untuk dibandingkan dengan standar yang lain. Waktu yang diperlukan untuk kegiatan memeriksa ini bergantung pada kecepatan operator menemukan perbedaan antara obyek dengan performans standard yang dibandingkan.Dari Tabel PTKTK Elemen kerja ini termasuk dalam efektif dan tidak dapat dihindari. Walaupun tedapat waktu tunggu tetapi masih tergolong efektif karena tangan yang menunggu dilakukan dengan memegang tube agar tidak jatuh. 
Tabel 20 PTKTK Vacuum dan Labeling

\begin{tabular}{|c|c|c|c|}
\hline Tangan Kiri & $\frac{\text { Waktu }}{\text { (detik) }}$ & Tangan Kanan & $\frac{\text { Waktu }}{\text { (detik) }}$ \\
\hline \multirow{4}{*}{ Menunggu } & \multirow{4}{*}{19.4} & Menjangkau Tube & 1.8 \\
\hline & & Memindahkan Ke Lori & 6.8 \\
\hline & & Mendorong Lori Ke Meja Vacuum & 9.2 \\
\hline & & Menjangkau Tube & 1.6 \\
\hline Memegang Tube & 2.9 & Meletakkan Tube Ke Meja Vacuum & 2.9 \\
\hline Memegang Valve & 0 & Memasukan Valve Ke Lubang Vacuum & 0 \\
\hline Sub Total & 22.3 & Sub Total & 22.3 \\
\hline Sub Total x 5 Tube & 111.5 & Sub Total $\times 5$ Tube & 111.5 \\
\hline \multirow{4}{*}{ Menunggu } & \multirow{4}{*}{18.6} & Menekan Valve & 13.5 \\
\hline & & Memasukan Inside Core Kedalam Valve & 2.1 \\
\hline & & \begin{tabular}{|l|} 
Menekan Tombol Airjet \\
\end{tabular} & 1.5 \\
\hline & & Memasukan Ke valve Lubang Vacuum & 1.5 \\
\hline Sub Total & 18.6 & Sub Total & 18.6 \\
\hline Sub Total $\times 5$ Tube & 93 & Sub Total $\times 5$ Tube & 93 \\
\hline Mengambil Cup & 2.9 & Menunggu & 2.9 \\
\hline Memutar Cup & 3.4 & Melepas Valve Dari Lubang Vacuum & 3.4 \\
\hline \multirow{3}{*}{ Menunggu } & \multirow{3}{*}{25.6} & Labelling & 2.1 \\
\hline & & Memindahkan Tube Ke Lori & 10 \\
\hline & & Mengantarkan Ke Booking Storage Sem & 13.5 \\
\hline Sub Total & 31.9 & Sub Total & 31.9 \\
\hline Sub Total $\times 5$ Tube & 159.5 & Sub Total $x 5$ Tube & 159.5 \\
\hline Total Waktu Tiap Sik & 364 & & 364 \\
\hline Jumlah Pcs Tiap Siklus & 5 Pcs & & 5 Pcs \\
\hline
\end{tabular}

Sumber: Data Pengamatan

Keterangan:

$=$ kegiatan yang dapat dihilangkan

Kegiatan memasukan valve ke lubang Vacuum atau biasa disebut pengempesan/ flatting sebaiknya cukup dilakukan satu kali saja, karena sama saja prosesnya setelah memasukan inside core. Sehingga bisa memaksimalkan waktu kerja. sehingga dari Tabel PTKTK didapatkan hasil sub total waktu x 5 tube dari menghilangkan kegiatan memasukan ke valve lubang vacuum sebelumnya 119,5 detik menjadi 115,5 detik.

\begin{tabular}{|c|c|c|c|}
\hline Tangan Kiri & $\begin{array}{l}\text { Waktu } \\
\text { (detik) }\end{array}$ & Tangan Kanan & $\begin{array}{l}\text { Waktu } \\
\text { (detik) }\end{array}$ \\
\hline Menunggu & & $\begin{array}{l}\text { Mengambil Tube Dari } \\
\text { Storege Sementara }\end{array}$ & \\
\hline Memegang Tube & 4.3 & Menjangkau Tube & 4.3 \\
\hline \multirow{4}{*}{ Menunggu } & \multirow{4}{*}{9} & Meletakkan Tube Ke Pallet & 1.6 \\
\hline & & \begin{tabular}{|l|l|} 
Merapikan Tube \\
\end{tabular} & 2.2 \\
\hline & & Menekan Tube & 2.4 \\
\hline & & Pewarnaan/Cat Valve & 2.8 \\
\hline Sub Total & 13.3 & Sub Total & 13.3 \\
\hline Sub Total x 5 Tube & 66.5 & Sub Total x 5 Tube & 66.5 \\
\hline Total Waktu Tiap Siklus & 66.5 & & 66.5 \\
\hline Jumlah Pcs Tiap Siklus & 5 Pcs & & 5 Pcs \\
\hline
\end{tabular}

Sumber: Data Pengamatan

Keterangan:

= kegiatan yang dapat dihilangkan

Kegiatan ini menunjukkan situasi yang tidak efektif yang dilakukan oleh operator (menunngu tube di distribusikan ke storage sementara, dengan mondar mandir hanya me- mastikan tube sudah divacuum \& labeling) sehingga perbaikan atau penanggulangan yang perlu dilakukan lebih ditujukan dengan merubah proses operasi kerjanya. Yaitu setelah tube divacuum dan labeling, di pindahkan ke Lori. Tube sebaiknya diarahkan langsung ke booking tube. Dengan ini bisa menghemat waktu proses kerja. Sehingga dari Tabel PTKTK didapatkan sebelumnya sub total $5 \mathrm{x}$ tube waktu proses 121.5 detik menjadi 66.5 detik.

6) Penentuan Allowance dan Waktu Standar setelah Perbaikan

Tabel 22 Perhitungan Waktu Normal (Setelah Perbaikan)

\begin{tabular}{|l|c|c|c|c|}
\hline \multicolumn{1}{|c|}{ Elemen Kerja } & $\begin{array}{c}\text { Waktu } \\
\text { Siklus } \\
\text { (detik) }\end{array}$ & $\begin{array}{c}\text { Rating } \\
\text { Faktor }\end{array}$ & $\begin{array}{c}\text { Waktu } \\
\text { Normal } \\
\text { (detik) }\end{array}$ & $\begin{array}{c}\text { Pembulatan } \\
\text { Waktu } \\
\text { Normal } \\
\text { (detik) }\end{array}$ \\
\hline $\begin{array}{l}\text { Part Tube Dan } \\
\text { Inflate Tube }\end{array}$ & 266.9 & 1.02 & $\mathbf{2 7 2 . 2 4}$ & $\mathbf{2 7 2}$ \\
\hline Inspection & 305,9 & 1.03 & $\mathbf{3 2 4 . 4 5}$ & $\mathbf{3 1 5}$ \\
\hline $\begin{array}{l}\text { Vacuum Dan } \\
\text { Labelling }\end{array}$ & 290.5 & 1.03 & $\mathbf{2 9 9 . 2 2}$ & $\mathbf{2 9 9}$ \\
\hline Booking & 53 & 1.02 & $\mathbf{5 4 . 0 6}$ & $\mathbf{5 4}$ \\
\hline
\end{tabular}

Sumber: Hasil Perhitungan

Tabel 23 Perhitungan Waktu Standar (Setelah Perbaikan)

\begin{tabular}{|l|c|c|c|c|}
\hline \multicolumn{1}{|c|}{ Elemen Kerja } & $\begin{array}{c}\text { Waktu } \\
\text { Normal } \\
\text { (Detik) }\end{array}$ & $\begin{array}{c}\text { Allowance } \\
\text { (\%) }\end{array}$ & $\begin{array}{c}\text { Waktu } \\
\text { Standar } \\
\text { (Detik) }\end{array}$ & $\begin{array}{c}\text { Pembulatan } \\
\text { (detik) }\end{array}$ \\
\hline $\begin{array}{l}\text { Part Tube Dan } \\
\text { Inflate Tube }\end{array}$ & 272 & 18 & 331.70 & 332 \\
\hline Inspection & 315 & 31 & 456.52 & 457 \\
\hline $\begin{array}{l}\text { Vacuum Dan } \\
\text { Labelling }\end{array}$ & 299 & 20 & 373.75 & 374 \\
\hline Booking & 54 & 13 & 62.06 & 62 \\
\hline
\end{tabular}

Sumber: Hasil Perhitungan

\section{KESIMPULAN DAN SARAN}

\section{Simpulan}

Berdasarkan hasil Pengumpulan Data, Pengolahan Data, dan Analisa Hasil, maka dapat disimpulkan:

1. Faktor yang mempengaruhi kinerja tidak efektif yaitu

a) Kurang disiplinnya operator karena budaya kerja;

b) Belum adanya standar kerja (gerak dan waktu);

c) Tingkat defect yang tinggi;

d) Terlambatnya distribusi tube dari proses kerja sebelumnya;

e) Peralatan usang;

f) Peralatan kurang memadai;

g) Adanya proses menunggu; dan

h) Penentuan allowance yang disamaratakan. 
2. Hasil perhitungan waktu standar sebelum perbaikan dan sesudah perbaikan yaitu:

Tabel 24 Perbandingan Waktu Standar Sebelum dan Setelah Perbaikan

\begin{tabular}{|l|c|c|c|c|}
\hline \multirow{2}{*}{ Kegiatan Kerja } & $\begin{array}{c}\text { Waktu standar } \\
\text { sebelum perbaikan }\end{array}$ & $\begin{array}{c}\text { Waktu standar } \\
\text { setelah perbaikan }\end{array}$ & Selisih & \multirow{2}{*}{ Persentase } \\
\cline { 2 - 4 } & \multicolumn{3}{|c|}{ Detik } & $(\%)$ \\
\hline Part Tube Dan Inflate Tube & 417 & 332 & 85 & 25.6 \\
\hline Inspection & 474 & 457 & 17 & 3.7 \\
\hline Vakum Dan Labelling & 447 & 374 & 73 & 19.5 \\
\hline Booking & 136 & 62 & 74 & 119.4 \\
\hline
\end{tabular}

Sumber: Hasil Perhitungan

Dari tabel-tabel tersebut diatas didapatkan persentase produktifitas sebelum dan sesudah perbaikan yaitu produktifitas dari $66,84 \%$ menjadi $84,83 \%$ perbaiakan metode kerja yang cukup signifikan kenaikan produktifitasnya dan waktu standar sebelum perbaikan dan setelahnya mengalami perubahan sebesar 25,6 \% atau sebelum perbaikan didapatkan waktu standar 417 detik, setelah perbaikan didapatkan waktu standar 332 detik pada kegiatan Part Tube Dan Inflate Tube, untuk kegiatan Inspection didapatkan perubahan waktu standar sebesar 3,7 $\%$ yaitu sebesar 474 detik sebelum perbaikan setelah perbaikan didapatkan waktu standar 457detik.

Pada Vakum Dan Labelling didapatkan waktu standar sebelum perbaikan 447 detik dan setelah perbaikan didapatkan waktu standar 374 detik atau mengalami perubahan 19,5\%. untuk kegiatan Booking didapatkan perubahan waktu standar sebesar 119,4\% yaitu sebesar 136 detik sebelum perbaikan setelah perbaikan didapatkan waktu standar 62 detik Data tersebut menunjukan metode time and motion study dapat meningkatkan standar waktu kerja sehingga dapat meningkatkan efektifitas waktu dan pergerakan kerja yang optimal.

\section{Saran}

a. Dapat digunakan rekomendasi pengukuran waktu kerja ini untuk diterapkan sebagai mengukur waktu standar perusahaan;

b. Melakukan perbaikan dan peremajaan mesin vakum dan inflate agar tidak menjadi penghambat kerja operator;

c. Pengadaan Lori dorong untuk transportasi distribusi tube. Sehingga bisa mengurangi waktu tunggu; dan

d. Meningkatkan kembali kinerja pekerja khususnya di Oem Tube Final Inspection.

\section{DAFTAR PUSTAKA}

Barnes, R. M. 1980. Motion and Time Study Design and Measurement of Work, 7th ed. John Willey and Sons, New York.

Bora, M.A \& irwan. 2017. Analisa Perhitungan Waktu Standard Service Ringan Untuk Meningkatkan Kepuasan Pelanggan. Jurnal Industry Stt Ibnu Sina, 2(1), 81-90.

Darsini. 2014. Penentuan Waktu Baku Produksi Kerupuk Rambak Ikan Laut Sari Enak Di Sukoharjo. Jurnal Teknik Industri, 12(2),113-247.

Erliana, CI.2015. Perbaikan Metode Kerja Pengantongan Semen Menggunakan Peta Tangan Kiri Dan Kanan. Spektrum Industri, 13(2), 115-228.

Gumilang, FR. 2017. Perancangan Peta Tangan Kanan Tangan Kiri Bagian After Market Divisi Packaging PT. Xyz Indonesia. Seminar dan Konferensi Nasional IDEC 2017, (433-441). Surakarta, Indonesia: Universitas Sebelas Maret.

Niebel B. W. 1988. Motion and Time Study. Irwin. Homewood, Illinois.

Novistiara, amal. 2017. Studi Waktu Dan Beban Kerja Untuk Penentuan Kebutuhan Dan Distribusi Pekerja Pada Alur Produksi Nanas Kaleng. Jurnal Keteknikan Pertanian, 5(1), 49-56.

Purnomo, H. 2004. Pengantar Teknik Industri. Edisi Kedua. Yogyakarta: Graha Ilmu.

Sutalaksana IZ, Anggawisastra R, dan Tjaakramaatmadja JH. 2006. Teknik Perancangan Sistem Kerja. ITB: Bandung.

Wignjosoebroto, S. 2003. Ergonomi Studi Gerak Dan Waktu: Teknik Analisis Untuk Peningkatan Produktivitas Kerja. Guna Widya: Surabaya. 